\title{
Vitamin D Insufficiency among Women Post-Partum in Northern Sweden-A Public Health Concern
}

\author{
Pamela Hasslöf ${ }^{1}$, Frida Karlsson Videhult ${ }^{2}$, Sven Arne Silfverdal ${ }^{2}$, Christina E. West ${ }^{2}$, \\ Christina Stecksén-Blicks ${ }^{1}$
}

${ }^{1}$ Department of Odontology, Pediatric Dentistry, Umeå University, Umeå, Sweden

${ }^{2}$ Department of Clinical Sciences, Pediatrics, Umeå University, Umeå, Sweden

Email: Christina.Stecksen-Blicks@umu.se

How to cite this paper: Hasslöf, P., Videhult, F.K., Silfverdal, S.A., West, C.E. and Stecksén-Blicks, C. (2017) Vitamin D Insufficiency among Women Post-Partum in Northern Sweden-A Public Health Concern. Food and Nutrition Sciences, 8, 99109.

http://dx.doi.org/10.4236/fns.2017.81007

Received: December 17, 2016

Accepted: January 16, 2017

Published: January 19, 2017

Copyright $\odot 2017$ by authors and Scientific Research Publishing Inc. This work is licensed under the Creative Commons Attribution International License (CC BY 4.0).

http://creativecommons.org/licenses/by/4.0/ c) (i) Open Access

\begin{abstract}
Pregnancy and post-partum represent a period of susceptibility for vitamin D insufficiency. This study investigated S-25 [OH] D levels in women in northern Sweden 4 weeks post-partum and its association with selected background factors. Blood from 100 healthy women were analyzed for iron status and serum levels of S-25[OH] D using ionization-mass spectrometry (HPLC-APCI-MS). $<50 \mathrm{nmol} / \mathrm{L}$ was categorized as insufficiency and $<25 \mathrm{nmol} / \mathrm{L}$ as deficiency. Maternal BMI, dietary habits, fungal infections during pregnancy, and infant birth characteristics were collected using questionnaires and medical charts. $58 \%$ were vitamin $\mathrm{D}$ insufficient whereas $10 \%$ had deficiency. Insufficiency was most common during winter $(\mathrm{OR}=2.77 ; 95 \% \mathrm{CI}=$ 1.1 - 6.96) and women with deficiency reported lower milk consumption; $11.3 \pm 22.8$ intakes per months vs. $34.0 \pm 28.9$ for those above $25 \mathrm{nmol} / \mathrm{L}(p<0.05)$. Vitamin D-insufficient women had lower serum ferritin levels $(p<0.01)$ and higher serum transferrin levels $(p<0.05)$. A history of vaginal fungal infection during pregnancy was associated with insufficiency $(\mathrm{OR}=5.10 ; 95 \% \mathrm{CI}=1.01-25.73)$, however, the confidence interval of the estimate was wide, resulting in uncertainty. It is concluded that vitamin $\mathrm{D}$ insufficiency 4 weeks post-partum was common in women living at $63^{\circ} 49^{\prime} \mathrm{N}$. The odds of being insufficient were increased during winter whereas milk consumption was negatively associated with deficiency. The low vitamin D-levels particularly during winter is a public health concern. From a public health perspective it has to be considered whether dietary advices alone should be modified or if supplementation with vitamin $\mathrm{D}$ during pregnancy and the post-partum period also is needed.
\end{abstract}

\section{Keywords}

Vitamin D Insufficiency, Fungal Infection, Postpartum, Public Health, Season 


\section{Introduction}

Vitamin D is acquired through synthesis in the epidermis after sun exposure and through the diet. Season of the year and latitude affect the amount of ultraviolet B radiation. Sun exposure is restricted during winter in northern Sweden since sun hours are few. Due to fear of skin cancer and premature ageing unprotected exposure to the sun has declined during the last decades. Dietary vitamin D is mostly derived from fortified milk products, egg, fatty fish and fish containing food. A recent Swedish study among young adults living in northern Sweden showed that low levels of vitamin D were common during winter even if the dietary vitamin $\mathrm{D}$ intake met the current national recommendations [1].

The importance of vitamin D for skeletal and dental mineralization is well known where sufficient vitamin D levels support mineralization by promoting calcium absorption in the gut. The association between vitamin $\mathrm{D}$ levels and chronic and infectious diseases has elicited an increasing scientific interest. Vitamin D modulates immune function influencing different cell types and it has been shown that vitamin D modify proinflammatory cytokine responses [2] [3] [4]. Further, patients with candidemia had lower levels of vitamin D [5]. Pregnancy and the following postpartum period is a period in life with pronounced vulnerability for vitamin D insufficiency. Vitamin D insufficiency in pregnant women has been observed in many parts of the world as well as an association between low vitamin $\mathrm{D}$ status and multiple potential negative pregnancy outcomes in both mother and child [6] [7] [8] [9] [10].

Serum levels of vitamin D are measured by analyzing 25 -hydroxy vitamin D concentration $(25[\mathrm{OH}] \mathrm{D})$. The optimal level for S-25[OH]D status is under debate but insufficiency is usually considered if concentration $<50 \mathrm{nmol} / \mathrm{L}$ and concentrations $<25$ $\mathrm{nmol} / \mathrm{L}$ is considered as deficiency [11] [12].

The primary aim of this study was to investigate whether women in the northern part of Sweden had sufficient S-25[OH]D levels 4 weeks postpartum. A secondary aim was to analyze the association of selected background factors and S-25[OH] D levels.

\section{Material and Methods}

\subsection{Study Design}

The study had a cross sectional design and the primary outcome measure was maternal S-25[OH]D concentrations 4 weeks post-partum. The cohort had previously been studied regarding prevalence of candida infection in infants during their first year of life [13]. As the study was explorative no power calculation was performed.

\subsection{Study Population and Ethical Approval}

The study was conducted in the city of Umeå, northern Sweden, latitude: $63^{\circ} 49^{\prime} \mathrm{N}$. A total of 120 healthy women of 4 -week old infants, were invited in a consecutive order at one well baby clinic. Of these, 20 did not consent to participate and the material thus includes 100 women aged (mean, (SD), range) 32 years, (4.5), $21-44$. The majority of the women were fair skinned, $46 \%$ were primiparas, $39 \%$ second time mothers and $15 \%$ had given birth to three or more children. No inclusions were performed in July due to 
vacation. The study was approved by the Regional Ethical Review Board in Umeå, Sweden (Dnr. 2010-218-31M and 2014-341-32M) and informed consent was obtained from the participating women.

\subsection{Women's Weight and Length}

Data on women's weight and length at the first and last visit during pregnancy were collected from charts at the maternity clinic. Data on weight and length were available for 86 women. Weight gain during pregnancy and body mass index (BMI) $\left(\mathrm{kg} / \mathrm{m}^{2}\right)$ were calculated.

\subsection{Mode of Delivery, Birth Weight, Feeding and Women's Diet}

At inclusion, consenting women were asked to fill in a questionnaire about delivery mode and birth weight and length, infant feeding mode (exclusive breast feeding, partial breast feeding or no breast feeding). The questionnaire also included questions regarding a) food intake, i.e. intake frequencies of milk products, eggs and fatty fish i.e. herring and salmon, b) health during pregnancy, i.e. fungal infections. The women were also asked to fill in questionnaires about infant feeding at follow-ups at 4 weeks, 2 , 3 and 6 months.

\subsection{Sampling of Blood and Analyses}

A maternal venous blood sample $(10 \mathrm{~mL})$ was collected in test tubes containing heparin. Blood was analyzed for hemoglobin, transferrin, and ferritin according to accredited methods at Laboratory Medicine at Umeå University Hospital. An aliquot of the blood sample was immediately centrifuged at $4000 \mathrm{G}$ for 10 minutes and the plasma was kept frozen at $-80^{\circ} \mathrm{C}$ until analysis of S-25[OH]D. S-25 [OH] D were analyzed according to high-pressure liquid chromatography-atmospheric pressure chemical ionization-mass spectrometry (HPLC-APCI-MS), (Vitas, Oslo, Norway); [1].

\subsection{Statistical Analyses}

The intake frequencies of milk products, fish and eggs were calculated as intake per months. The data were analyzed using PASW statistics software (version 22.0, Chicago, IL, USA). For univariate comparisons ANOVA was applied for continuous data and Chi-square or Fisher's exact tests for comparison of categorical variables. Variables with a statistically significant or close to statistically significant association with insufficiency and deficiency in S-25[OH] D levels were analysed in logistic regressions models to ascertain their effects on the outcome a) S-25[OH]D levels $<50 \mathrm{nmol} / \mathrm{L}$; season, fungal infection in pregnancy, haemoglobin, transferrin, ferritin and exclusive breastfeeding up to 3 months of age b) S-25[OH]D levels $<25 \mathrm{nmol} / \mathrm{L}$; milk intakes per months. A $p$-value of $<0.05$ was considered as statistically significant.

\section{Results}

\subsection{S-25[OH]D Levels}

Among the mothers, S-25[OH] D levels varied between 20.2 and $152.5 \mathrm{nmol} / \mathrm{L}$ with a 
mean (SD) $48.9(22.2) \mathrm{nmol} / \mathrm{L}$. In all, 58 percent of the women had S-25[OH]D levels < $50 \mathrm{nmol} / \mathrm{L}$ and 10 percent $<25 \mathrm{nmol} / \mathrm{L}$ (Figure 1 ).

\subsection{S-25[0H]D Levels and Background Factors-Univariable Comparisons}

\subsubsection{Season}

The highest S-25[OH]D levels were seen in September and the lowest levels in January (Figure 2). During November to March 67\% were insufficient compared to $48 \%$ during April to October $(p<0.05)$.

\subsubsection{Iron Status}

As depicted in Table 1, vitamin D-insufficient women had lower serum ferritin levels $(p<0.01)$ and higher serum transferrin levels $(p<0.05)$. The serum hemoglobin levels

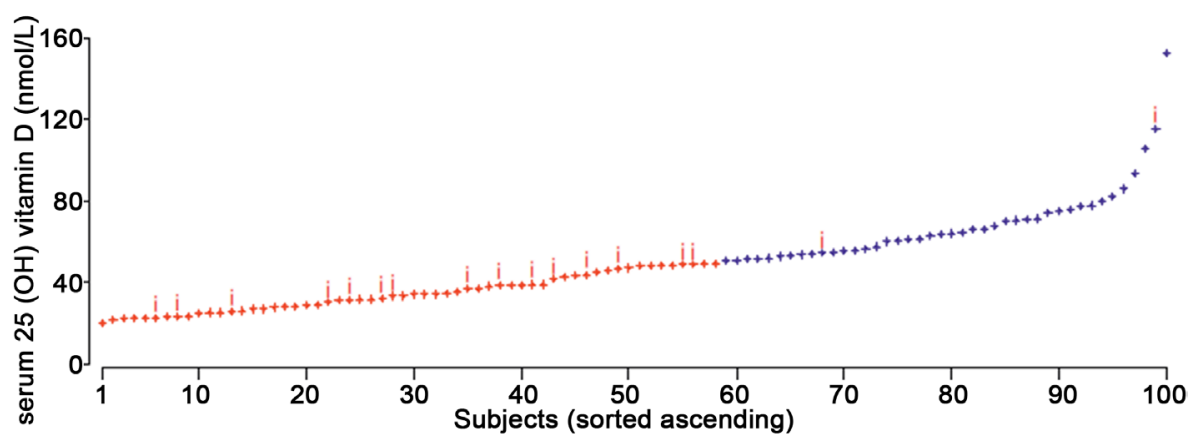

Figure 1. Distribution of S-25[OH]D levels in mothers 4 weeks postpartum. X-axis denotes each participant $(n=100)$. Red color illustrates participants with insufficient levels and blue color sufficient levels. Y-axis denotes vitamin S-25[OH]D levels (nmol/L). Red “i” denotes participants with fungal infection

Table 1. Weight variables, iron status, calcium, milk, fat fish and egg consumption in women and delivery, birth weight and length of the children. ${ }^{\star} p<0.05,{ }^{* *} p<0.01$.

\begin{tabular}{|c|c|c|c|}
\hline & $\begin{aligned} \text { Sufficient } & \geq 50 \mathrm{nmol} / \mathrm{L} \\
(\mathrm{n}=42) & =\end{aligned}$ & $\begin{array}{c}\text { Insufficient }<50 \mathrm{nmol} / \mathrm{L} \\
(\mathrm{n}=58)\end{array}$ & $p$ \\
\hline \multicolumn{4}{|l|}{ Women } \\
\hline Weight (kg) start* & $65.8 \pm 9.9$ & $64.1 \pm 11.5$ & 0.407 \\
\hline Weight $(\mathrm{kg})$ end $^{*}$ & $78.6 \pm 11.6$ & $79.4 \pm 10.4$ & 0.761 \\
\hline BMI start* & $23.6 \pm 3.5$ & $23.5 \pm 3.4$ & 0.839 \\
\hline BMI end* & $28.6 \pm 4.1$ & $28.7 \pm 3.8$ & 0.959 \\
\hline Haemoglobin $(\mu \mathrm{mol} / \mathrm{L})$ & $17.2 \pm 6.1$ & $14.7 \pm 6.5$ & 0.057 \\
\hline Transferrin $(g / L)$ & $2.4 \pm 0.4$ & $2.5 \pm 0.4^{*}$ & 0.029 \\
\hline Ferritin $(\mu \mathrm{g} / \mathrm{L})$ & $82.0 \pm 52.3$ & $53.9 \pm 37.6^{\star *}$ & 0.002 \\
\hline Milk (intake/months) & $33.8 \pm 28.6$ & $30.1 \pm 29.5$ & 0.536 \\
\hline Fish (fat) (intake/months) & $4.1 \pm 2.6$ & $3.7 \pm 4.0$ & 0.559 \\
\hline Eggs (intake/months) & $10.3 \pm 13.8$ & $9.9 \pm 9.7$ & 0.922 \\
\hline \multicolumn{4}{|l|}{ Children } \\
\hline Delivery before 37 weeks & 2 & 0 & 0.174 \\
\hline Delivery with caesarean section (n) & 5 & 6 & 0.537 \\
\hline Birth weight $(\mathrm{g})$ & $3473 \pm 461$ & $3610 \pm 2478$ & 0.155 \\
\hline Birth length (cm) & $50.2 \pm 2.5$ & $50.9 \pm 2.1$ & 0.156 \\
\hline
\end{tabular}

${ }^{*}$ Data retrieved from 86 women. 


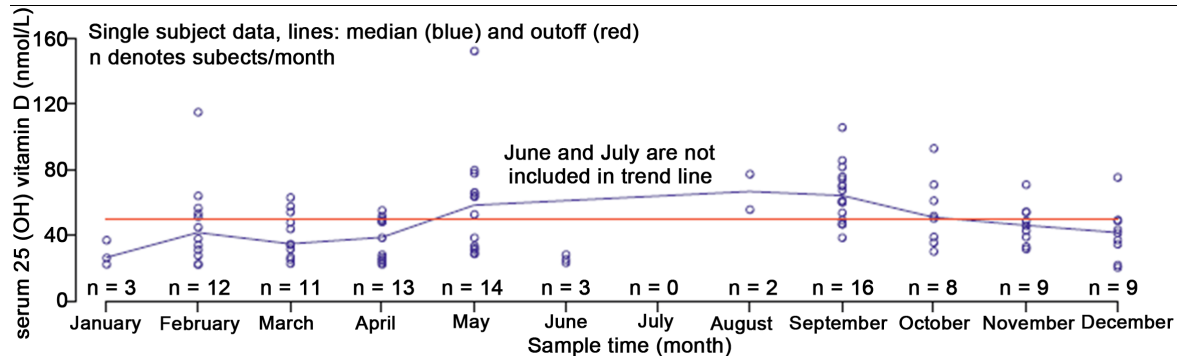

Figure 2. Seasonal variation in S-25[OH]D levels. Each participant is illustrated with a blue circle. X-axis illustrates months and Y-axis serum S-25[OH]D levels. Women above the red line have sufficient S-25[OH]D levels ( $\geq 50 \mathrm{nmol} / \mathrm{L})$.

were slightly lower in vitamin $\mathrm{D}$-insufficient women but the difference fell just short of the significance level $(p=0.057)$.

\subsubsection{BMI}

The weight gain during pregnancy was $13.6 \pm 4.1$ kilogram vs. $14.6 \pm 5.8$ kilogram in the sufficient and the insufficient group, respectively. No relationship between initial BMI or weight gain during pregnancy and S-25[OH]D levels post-partum was observed $(p>0.05)$.

\subsubsection{Reported Food Intake}

The intakes of fatty fish, milk and eggs did not differ between women with vitamin D insufficiency and those with sufficient levels $(p>0.05)$, (Table 1$)$. Women with deficiency reported a lower number of intakes of milk per month $11.3 \pm 22.8$ vs. $34.0 \pm 28.9$ compared to those above the threshold value $(p<0.05)$. The corresponding intakes of fatty fish per months were $2.3 \pm 1.4$ and $4.0 \pm 3.6$, respectively $(p>0.05)$.

\subsubsection{Fungal Infection during Pregnancy}

Seventeen percent of the mothers had a history of vaginal fungal infection during pregnancy and in the vitamin D insufficient group it was more common $(26 \%$ vs. $5 \%$ ( $p<$ 0.01), (Figure 1).

\subsubsection{Delivery Mode, Birth Weight and Length}

The rate of caesarean section was $11 \%$ and there were no differences between the groups with insufficient and sufficient levels of S-25[OH]D $(p>0.05)$. Nor were there any differences in birth weight and birth length (Table 1).

\subsubsection{Breastfeeding}

Exclusive breastfeeding at 4 weeks, 2, 3 and 6 months is presented in Figure 3. Mothers with sufficient S-25[OH] D levels were more likely to exclusively breastfeed their infants compared to the insufficient group of mothers up to 3 months of age $(p<0.05)$.

\subsection{S-25[0H]D Levels and Background Factors-Multivariable Comparisons}

The variables and the outcomes of the multivariable comparisons are listed in Table 2. For insufficiency $(<50 \mathrm{nmol} / \mathrm{L})$ the model was statically significant $\chi^{2}=24.682 ; p<$ 0.001 , and explained $30 \%$ of the variance (Nagelkerke $\mathrm{R}^{2}$ ) and correctly classified $68 \%$ 


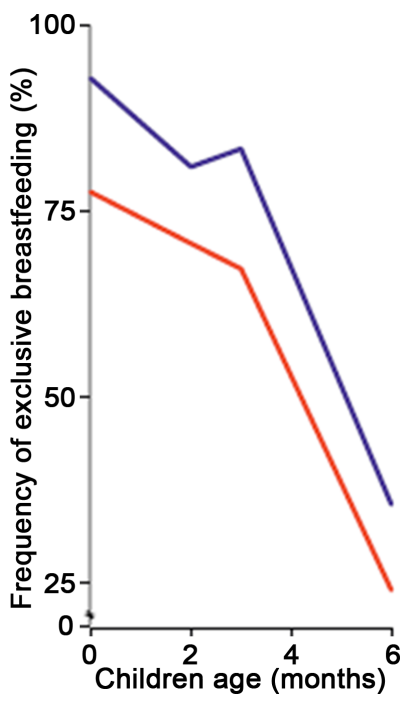

Figure 3. Exclusive breastfeeding in relation to S-25[OH]D levels. X-axis denotes children's age in months. Y-axis denotes\% women exclusively breastfeeding their children. Blue line represents women with sufficient S-25[OH]D level $(\geq 50 \mathrm{nmol} / \mathrm{L})$, red line represents women with insufficient S-25[OH]D levels $(<50 \mathrm{nmol} / \mathrm{L})$.

Table 2. Variables in the logistic regression models for analysis of 25-hydroxy vitamin D insufficiency and deficiency.

\begin{tabular}{|c|c|c|c|c|}
\hline S-25[OH]D & Variables & OR & $95 \% \mathrm{CI}$ & $\mathrm{p}$ \\
\hline & Winter (November-March) & & & \\
\hline & No & Ref. & & \\
\hline & Yes & 2.77 & $1.1-6.96$ & 0.031 \\
\hline & Fungal infection in pregnancy & & & \\
\hline & No & Ref & & \\
\hline & Yes & 5.10 & $1.01-25.73$ & 0.049 \\
\hline \multirow[t]{6}{*}{$<50 \mathrm{nmol} / \mathrm{L}$} & Haemoglobin $(\mu \mathrm{mol} / \mathrm{L})$ & 0.98 & $0.98-1.06$ & 0.578 \\
\hline & Transferrin $(\mathrm{g} / \mathrm{L})$ & 1.59 & $0.98-2.57$ & 0.061 \\
\hline & Ferritin $(\mu \mathrm{g} / \mathrm{L})$ & 0.99 & $0.98-1.01$ & 0.188 \\
\hline & $\begin{array}{l}\text { Exclusive breastfeeding up to } \\
3 \text { months of age of the child }\end{array}$ & & & \\
\hline & No & Ref. & & \\
\hline & Yes & 0.472 & $0.16-1.4$ & 0.177 \\
\hline$<25 \mathrm{nmol} / \mathrm{L}$ & Milk (intakes/months) & 0.91 & $0.87-0.95$ & 0.000 \\
\hline
\end{tabular}

of the cases. Winter increased the likelihood of insufficiency ( $\mathrm{OR}=2.77 ; 95 \% \mathrm{CI}=1.1$ 6.96) as well as a history of maternal fungal infection during pregnancy ( $\mathrm{OR}=5.10$; $95 \% \mathrm{CI}=1.01-25.73)$. Serum levels of haemoglobin, transferrin, ferritin as well as exclusive breastfeeding up to 3 months of age did not add significantly to the model. For deficiency $(<25 \mathrm{nmol} / \mathrm{L})$ the model was statistically significant $\chi^{2}=70.58 ; P<0.001$, explained $68 \%$ of the variance (Nagelkerke $\mathrm{R}^{2}$ ) and correctly classified $88 \%$ of the cases. Number of milk intakes per months was negatively associated with deficiency (OR = $0.91 ; 95 \% \mathrm{CI}=0.87-0.95)$. 


\section{Discussion}

\subsection{Prevalence of Vitamin D Insufficiency}

Vitamin D insufficiency was common in this cohort of women living at latitude $63^{\circ} 49^{\prime} \mathrm{N}$ in northern Sweden. There was a clear seasonal variation in S-25[OH]D levels with the lowest levels in January. The odds of being insufficient had a 2.8 fold increase during November to March indicating the importance of sun exposure, which confirms a recent report by Lundqvist et al. from the same area [14]. Our data from the postpartum period are also in agreement with a review of 14 studies from different geographical areas reporting a mean S-25[OH]D concentration during pregnancy or at delivery ranging from $12.8 \mathrm{nmol} / \mathrm{L}$ to $138.5 \mathrm{nmol} / \mathrm{L}$ [6]. The few studies that have targeted Swedish women during pregnancy have reported a majority of woman to be below recommended levels of S-25[OH]D. In late pregnancy $65 \%$ of fair-skinned Swedish mothers living at latitude $57^{\circ} \mathrm{N}-58^{\circ} \mathrm{N}$ had insufficient levels during wintertime [15] which is similar to our findings from latitude $63^{\circ} \mathrm{N} 4$ weeks post-partum. Brembeck et al. suggested that higher vitamin $\mathrm{D}$ intake may be needed during the winter for fairskinned pregnant women at northern latitudes to avoid vitamin D insufficiency [15]. Additionally vitamin D deficiency has been shown in Somali woman living in the middle of Sweden in early pregnancy [16].

\subsection{Food Intake and Vitamin D Insufficiency}

Vitamin D insufficiency may reflect a less adequate diet as it was associated with worse iron status. Women with deficiency reported lower consumption of milk while there were no differences in the intake frequencies of milk, fatty fish or eggs between insufficient women and women with sufficient levels of vitamin D. The validity of the food frequency questionnaire we used may suffer from biases when used on the individual level [17]; mainly due to recall bias but also because the study group of mothers postpartum may experience a change in lifestyle conditions including dietary intakes. The reported intakes of fatty fish were low and averaged around 4 intakes per months. The National Food Agency in Sweden recommends pregnant women an intake of fish and seafood 2 - 3 times a week [18]. The low intake of fish is a concern and may be a consequence of the general recommendation in Sweden that consumption of fish from the Baltic, the southern part of the Gulf of Bothnia and the Gulf of Bothnia should be restricted to 2 - 3 times per year because of expected high levels of PCB, dioxin and mercury [18]. This recommendation may influence fertile women to unnecessarily avoid fish in general.

Breastfeeding has beneficial health effects for both the mother and child [19] [20]. In the univariable comparisons vitamin D insufficient women were less likely to exclusively breastfeed their babies. Although the association with breastfeeding could not be confirmed in the multivariable analyses it is an interesting finding which needs to be further investigated.

\subsection{Health and Vitamin D Insufficiency}

A novel finding in the present study is the five-fold increase in the risk of being insufficient in vitamin D in women with a history of fungal infection during pregnancy. From 
the longitudinal data by Lundqvist et al. [14] it can be assumed that mothers in the present study who were insufficient post-partum may also have been insufficient during pregnancy. Although the confidence interval of the estimate was wide, resulting in uncertainty, these findings could be consistent with studies reporting vitamin D insufficiency to be associated with susceptibility to a variety of infections as for example respiratory tract infections and candidemia [5] [21] and that vitamin D modulates the immune response to Candida [2]. Cut-off levels for vitamin D were originally set in relation to the role of vitamin $\mathrm{D}$ in bone mineralization, with levels $<25 \mathrm{nmol} / \mathrm{L}$ (10 $\mathrm{ng} / \mathrm{mL})$ often referred to vitamin D deficiency and $<50 \mathrm{nmol} / \mathrm{L}(20 \mathrm{ng} / \mathrm{mL})$ as vitamin D insufficiency [11], both associated with decreased bone mineralization and increased fracture risk. The optimal levels during pregnancy have so far not been set. However, pregnant women with vitamin D insufficiency are at increased risk of infections [9] [22] [23] [24] [25]. This may have implications also for the fetus as intrauterine infection is proposed to cause preterm birth [26]. Bodnar et al. [27] showed in a large observational pregnancy cohort study in North America that vitamin D levels below $<50$ $\mathrm{nmol} / \mathrm{L}$ during pregnancy is a risk factor for preterm birth with a dose response association and a recent meta-analysis with 10,098 participants indicated an association between low vitamin D levels and an increased risk of preterm birth (OR = 1.29); [28]. The increased risk could not be confirmed in the present study. Although the number of participants was relatively small, the investigated group represented a homogenous group of women with good socioeconomic conditions and access to healthy food in a limited geographical area.

\subsection{Public Health Implications}

The low vitamin D levels in mothers particularly during winter is a public health concern and may have impact on both mother and child health. In the UK a daily vitamin D supplementation of $10 \mu \mathrm{g}$ is recommended by the Department of Health to pregnant and lactating mothers [29]. A systematic review [30] on the effects of vitamin D supplementation during pregnancy on neonatal 25-hydroxyvitamin $\mathrm{D}(25(\mathrm{OH}) \mathrm{D})$ and calcium concentrations included randomized controlled trials that supplemented subjects with vitamin D2 or D3 during pregnancy and reported cord blood 25(OH)D or calcium concentrations. The authors suggested that women at risk for vitamin D deficiency, such as having a winter pregnancy or dark skin, should have their serum 25(OH)D level screened and take measures to assure a normal range of serum $25(\mathrm{OH}) \mathrm{D}$ concentration during pregnancy. In Sweden there are no specific recommendations of vitamin D supplementation to pregnant women and the levels of vitamin $\mathrm{D}$ is not measured routinely at the maternal health clinic, while measuring iron status is a well-established routine during prenatal care. Our results together with previous research [15] [16] indicate that promotion of an increased intake of foods rich in vitamin D and vitamin D supplementation during pregnancy and postpartum to Swedish mothers should be considered.

\section{Conclusion}

In summary, vitamin $\mathrm{D}$ insufficiency was common four weeks post-partum and our 
findings may have implications for maternal and infant short and long-term health. From a public health perspective, it has to be considered whether dietary advices alone should be modified or if supplementation with vitamin D during pregnancy and the post-partum period is also needed.

\section{Acknowledgements}

We would like to thank all participating women for their contribution. Further, we would like to thank Elisabeth Granström for technical support. This study was founded by financial support provided through regional agreement between Umeå University and Västerbotten County Council on cooperation in the field of Medicine, Odontology and Health (TUA).

Author contributions: SAS, CW, and CSB designed the study. PH analyzed the data, designed figures, and drafted the first version of the manuscript together with CSB. FKV participated with analyses of dietary data. $\mathrm{PH}, \mathrm{CW}$ and CSB wrote the final version of the manuscript. All authors read and approved the final manuscript.

\section{References}

[1] Persson, K., Ohlund, I., Nordstrom, L., Winberg, A., Ronmark, E. and West, C.E. (2013) Vitamin D Deficiency at the Arctic Circle-A Study in Food-Allergic Adolescents and Controls. Acta Paediatrica, 102, 644-649. https://doi.org/10.1111/apa.12172

[2] Khoo, A.L., Chai, L.Y., Koenen, H.J., Kullberg, B.J., Joosten, I., van der Ven, A.J. and Netea, M.G. (2011) 1, 25-Dihydroxyvitamin D3 Modulates Cytokine Production Induced by Candida Albicans: Impact of Seasonal Variation of Immune Responses. Journal of Infectious Diseases, 203, 122-130. https://doi.org/10.1093/infdis/jiq008

[3] Sun, J. (2010) Vitamin D and Mucosal Immune Function. Current Opinion in Gastroenterolology, 26, 591-595. https://doi.org/10.1097/MOG.0b013e32833d4b9f

[4] Lucas, R.M., Gorman, S., Geldenhuys, S. and Hart, P.H. (2014) Vitamin D and Immunity. F1000 Prime Reports, 6, 118. https://doi.org/10.12703/P6-118

[5] Lim, J.H., Ravikumar, S., Wang, Y.M., Thamboo, T.P., Ong, L., Chen, J., Goh, J.G., Tay, S.H., Chengchen, L., Win, M.S., Leong, W., Lau, T., Foo, R., Mirza, H., Tan, K.S., Sethi, S., Khoo, A.L., Chng, W.J., Osato, M., Netea, M.G., Wang, Y. and Chai, L.Y. (2015) Bimodal Influence of Vitamin D in Host Response to Systemic Candida Infection-Vitamin D Dose Matters. Journal of Infectious Diseases, 212, 635-644. https://doi.org/10.1093/infdis/jiv033

[6] Dawodu, A. and Akinbi, H. (2013) Vitamin D Nutrition in Pregnancy: Current Opinion. International Journal of Women's Health, 5, 333-343. https://doi.org/10.2147/IJWH.S34032

[7] Al-Hamaq, A.O. and Saleh, N.M. (2013) Association between Vitamin D Insufficiency and Adverse Pregnancy Outcome: Global Comparisons. International Journal of Women's Health, 5, 523-531.

[8] Olmos-Ortiz, A., Avila, E., Durand-Carbajal, M. and Diaz, L. (2015) Regulation of Calcitriol Biosynthesis and Activity: Focus on Gestational Vitamin D Deficiency and Adverse Pregnancy Outcomes. Nutrients, 7, 443-480. https://doi.org/10.3390/nu7010443

[9] Dawodu, A., Davidson, B., Woo, J.G., Peng, Y.M., Ruiz-Palacios, G.M., de Lourdes Guerrero, M. and Morrow, A.L. (2015) Sun Exposure and Vitamin D Supplementation in Relation to Vitamin D Status of Breastfeeding Mothers and Infants in the Global Exploration of Human Milk Study. Nutrients, 7, 1081-1093. https://doi.org/10.3390/nu7021081

[10] Weinert, L.S. and Silveiro, S.P. (2015) Maternal-Fetal Impact of Vitamin D Deficiency: A Critical Review. Maternal and Child Health Journal, 19, 94-101. 
https://doi.org/10.1007/s10995-014-1499-7

[11] Holick, M.F., Binkley, N.C., Bischoff-Ferrari, H.A., Gordon, C.M., Hanley, D.A., Heaney, R.P., Murad, M.H. and Weaver, C.M. (2012) Guidelines for Preventing and Treating Vitamin D Deficiency and Insufficiency Revisited. The Journal of Clinical Endocrinology and Metabolism, 97, 1153-1158. https://doi.org/10.1210/jc.2011-2601

[12] Braegger, C., Campoy, C., Colomb, V., Decsi, T., Domellof, M., Fewtrell, M., Hojsak, I., Mihatsch, W., Molgaard, C., Shamir, R., Turck, D. and van Goudoever, J. (2013) Vitamin D in the Healthy European Paediatric Population. Journal of Pediatric Gastroenterololy and Nutrition, 56, 692-701. https://doi.org/10.1097/MPG.0b013e31828f3c05

[13] Stecksen-Blicks, C., Granstrom, E., Silfverdal, S.A. and West, C.E. (2015) Prevalence of Oral Candida in the First Year of Life. Mycoses, 58, 550-556. https://doi.org/10.1111/myc.12355

[14] Lundqvist, A., Sandstrom, H., Stenlund, H., Johansson, I. and Hultdin, J. (2016) Vitamin D Status during Pregnancy: A Longitudinal Study in Swedish Women from Early Pregnancy to Seven Months Postpartum. PLoS ONE, 11, e0150385.

https://doi.org/10.1371/journal.pone.0150385

[15] Brembeck, P., Winkvist, A. and Olausson, H. (2013) Determinants of Vitamin D Status in Pregnant Fair-Skinned Women in Sweden. British Journal of Nutrition, 110, 856-864. https://doi.org/10.1017/S0007114512005855

[16] Saaf, M., Fernell, E., Kristiansson, F., Barnevik Olsson, M., Gustafsson, S.A. and Bagenholm, G. (2011) Severe Vitamin D deficiency in Pregnant Women of Somali Origin Living in Sweden. Acta Paediatrica, 100, 612-614. https://doi.org/10.1111/j.1651-2227.2011.02134.x

[17] Forster, H., Fallaize, R., Gallagher, C., O’Donovan, C.B., Woolhead, C., Walsh, M.C., Macready, A.L., Lovegrove, J.A., Mathers, J.C., Gibney, M.J., Brennan, L. and Gibney, E.R. (2014) Online Dietary Intake Estimation: The Food4Me Food Frequency Questionnaire. Journal of Medical Internet Research, 16, e150. https://doi.org/10.2196/jmir.3105

[18] The Swedish National Food Agency (Livsmedelsverket) (2008) Råd om mat till dig som är gravid; Elanders Sverige AB, Uppsala. (In Swedish)

[19] Chen, A. and Rogan, W.J. (2004) Breastfeeding and the Risk of Postneonatal Death in the United States. Pediatrics, 113, e435-439. https://doi.org/10.1542/peds.113.5.e435

[20] Schwarz, E.B., Ray, R.M., Stuebe, A.M., Allison, M.A., Ness, R.B., Freiberg, M.S. and Cauley, J.A. (2009) Duration of Lactation and Risk Factors for Maternal Cardiovascular Disease. Obstetrics and Gynecology, 113, 974-982. https://doi.org/10.1097/01.AOG.0000346884.67796.ca

[21] Ginde, A.A., Mansbach, J.M. and Camargo Jr., C.A. (2009) Association between Serum 25-Hydroxyvitamin D Level and Upper Respiratory Tract Infection in the Third National Health and Nutrition Examination Survey. Archives of Internal Medicine, 169, 384-390. https://doi.org/10.1001/archinternmed.2008.560

[22] Aghajafari, F., Nagulesapillai, T., Ronksley, P.E., Tough, S.C., O’Beirne, M. and Rabi, D.M. (2013) Association between Maternal Serum 25-Hydroxyvitamin D Level and Pregnancy and Neonatal Outcomes: Systematic Review and Meta-Analysis of Observational Studies. British Medical Journal, 346, f1169. https://doi.org/10.1136/bmj.f1169

[23] Dunlop, A.L., Taylor, R.N.; Tangpricha, V., Fortunato, S. and Menon, R. (2011) Maternal Vitamin D, Folate, and Polyunsaturated Fatty Acid Status and Bacterial Vaginosis during Pregnancy. Infectious Diseases in Obstetrics and Gynecology, 2011, Article ID: 216217. https://doi.org/10.1155/2011/216217

[24] Bodnar, L.M., Krohn, M.A. and Simhan, H.N. (2009) Maternal Vitamin D Deficiency Is Associated with Bacterial Vaginosis in the First Trimester of Pregnancy. Journal of Nutition, 139, 1157-1161. https://doi.org/10.3945/jn.108.103168 
[25] Hensel, K.J., Randis, T.M., Gelber, S.E. and Ratner, A.J. (2011) Pregnancy-Specific Association of Vitamin D Deficiency and Bacterial Vaginosis. American Journal of Obstetrics and Gynecology, 204, 41.e1-41.e9. https://doi.org/10.1016/j.ajog.2010.08.013

[26] Romero, R., Mazor, M., Munoz, H., Gomez, R., Galasso, M. and Sherer, D.M. (1994) The Preterm Labor Syndrome. Annals of the New York Academy of Sciences, 734, 414-429. https://doi.org/10.1111/j.1749-6632.1994.tb21771.x

[27] Bodnar, L.M., Platt, R.W. and Simhan, H.N. (2015) Early-Pregnancy Vitamin D Deficiency and Risk of Preterm Birth Subtypes. Obstetrics and Gynecology, 125, 439-447. https://doi.org/10.1097/AOG.0000000000000621

[28] Qin, L.L., Lu, F.G., Yang, S.H., Xu, H.L. and Luo, B.A. (2016) Does Maternal Vitamin D Deficiency Increase the Risk of Preterm Birth: A Meta-Analysis of Observational Studies. Nutrients, 8, 301. https://doi.org/10.3390/nu8050301

[29] Saraff, V. and Shaw, N. (2015) Sunshine and Vitamin D. Archives of Disease in Childhood, 101, 190-192. https://doi.org/10.1136/archdischild-2014-307214

[30] Yang, N., Wang, L., Li, Z., Chen, S., Li, N. and Ye, R. (2014) Effects of Vitamin D Supplementation during Pregnancy on Neonatal Vitamin D and calcium Concentrations: A Systematic Review and Meta-Analysis. Nutrition Research, 35, 547-556.

https://doi.org/10.1016/j.nutres.2015.04.010

Submit or recommend next manuscript to SCIRP and we will provide best service for you:

Accepting pre-submission inquiries through Email, Facebook, LinkedIn, Twitter, etc. A wide selection of journals (inclusive of 9 subjects, more than 200 journals)

Providing 24-hour high-quality service

User-friendly online submission system

Fair and swift peer-review system

Efficient typesetting and proofreading procedure

Display of the result of downloads and visits, as well as the number of cited articles

Maximum dissemination of your research work

Submit your manuscript at: http://papersubmission.scirp.org/

Orcontact fns@scirp.org 